\title{
EL DISCURSO MÍTICO DE LA EDAD MEDIA EN LA HISTORIA GENERAL DE ESPAÑA DE MODESTO LAFUENTE
}

\author{
Mònica Fuertes Arboix \\ Coe College
}

\section{Resumen}

Modesto Lafuente es el artífice de la Historia General de España escrita en el siglo XIX, redacción a la que dedicó los últimos años de su vida. La visión de España que se describe en sus páginas es la de un país constituido como tal desde la antigüedad. Esta visión mítica y fundacional de España responde, entre otras causas, al discurso político nacionalista del siglo XIX: la búsqueda en el pasado para justificar el presente y construir un futuro en el que los españoles como nación social y política se puedan identificar. En este trabajo tratamos de los elementos que se vale Lafuente para construir ese discurso mítico y en la influencia de ese discurso en la España contemporánea.

Palabras Clave: Modesto Lafuente, mito, historia, nacionalismo español, discurso mítico.

\section{Abstract}

Modesto Lafuente is the author of the Historia General de España written in the $19^{\text {th }}$ century, to what he dedicated the last years of his life. The vision of Spain described in this work is that of a country constituted as such since antiquity. This mythic and foundational vision of Spain has to do, among other things, to the national and political discourse common in $19^{\text {th }}$ century Spain, and that mainly deals with the idea of searching the past to justify the present, in order to build a future where the Spanish people can identify themselves as a social and political nation. In this paper we discuss the different elements used by Lafuente to construct this mythic discourse, and the influence that this discourse has even in contemporary Spain.

KEY WORDS: Modesto Lafuente, myth, History, Spanish nationalism, discourse.

«Lo presente, producto del pasado, engendra a su vez el futuro» Modesto Lafuente, Historia General de España. Discurso preliminar.

El siglo XIX es el marco idóneo para la mitificación de la historia de las naciones. 
La búsqueda en el pasado de vidas heroicas y ejemplares pretende explicar el carácter del pueblo constituido como nación y defender un pasado ideal en el que se supone que la vida en sociedad era mucho mejor. Son relatos de tiempos épicos que han de volver y que rescatarán al pueblo de un presente desafortunado. Recuerdan lo que somos mediante la narración de lo que fuimos y aspiran a mantener la esperanza de que ese tiempo épico pueda volver. La formación de la identidad nacional es un largo proceso que suele empezar en el medievo y que se explota en el romanticismo como inherente al concepto de nación, «una entidad cultural impelida a actuar como entidad política» y en donde la cultura se convierte «en la base esencial y única, de la diferenciación nacional» ${ }^{1}$.

En este trabajo me refiero a la Historia General de España escrita en el siglo XIX por Modesto Lafuente y Zamalloa (1806-1866), periodista satírico, escritor de costumbres, historiador y político, y quizás uno de los mejores y más populares escritores del siglo XIX junto con Larra y Mesonero Romanos. La particularidad de Lafuente reside en que dedicó gran parte de su vida a la redacción de la monumental Historia General de España, precisamente con el propósito de rescatar de la nostalgia una idea mítica de España difícil de encontrar en el presente caótico contemporáneo al autor. Por la naturaleza de este volumen de artículos, vamos a enfocar este trabajo en el estudio del periodo que comprende el tiempo histórico durante los reinados de Juan I, Enrique III y Juan II analizando cómo Lafuente articula y construye su discurso y se aleja de la visión científica y académica que debiera caracterizar el estudio riguroso de la historia.

La influencia de Modesto Lafuente en el panorama político y social español es todavía palpable. Cuando escuchamos en las noticias hablar de la ruptura del nacionalismo español, de los buenos y malos españoles, y del remoto origen de España como nación, escuchamos algunos de los mismos argumentos que Lafuente construía ya desde las páginas de la Historia General de España, donde la nación se presenta dotada de alma y carácter y existente desde tiempos inmemorables, con rasgos culturales y religiosos comunes que homogeneizan a sus ciudadanos dándoles signos de identidad común. La Historia es la ciencia responsable de definir la nación, de aportar argumentos que expliquen a los ciudadanos quiénes son, de dónde vienen y a dónde se dirigen, y Modesto Lafuente fue el gran artífice de la creación del mito fundacional de la nación española en el siglo XIX.

Entendemos por mito lo que Fernando García de Cortázar define como la «suprema ficción que en la antigüedad el poeta interponía al horror que le inspiraba lo

${ }^{1}$ T. Pérez Viejo, Nación, identidad nacional y otros mitos nacionalistas, Oviedo, Ediciones Nobel, 1999, p. 46. 
desconocido o la invención que hizo brotar la Europa de las naciones en el siglo XIX»². Lafuente es, así pues, un creador de fábulas que distorsiona el pasado dando a las cosas una apariencia más valiosa de lo que en realidad son, e incluso haciéndolas pasar por verdad. En el contexto del siglo xIx europeo se intuye la necesidad de cambiar a los protagonistas de la historia, porque ya no son solo los reyes los que encabezan el relato sino que ahora el conjunto de los ciudadanos, el pueblo, es lo determinante y decisivo para el desarrollo de la nación, y como tal debe aparecer reflejado en la historia de un país. Como muchos historiadores del XIX Lafuente construye un nacionalismo oficial basándose en «una historia codificada por las instituciones estatales como historia nacional y en la que el pasado de la nación se confunde con el del Estado»³.

Puede parecer que la faceta de escritor costumbrista satírico esté desligada de la de historiador, pero lo cierto es que la descripción minuciosa de la realidad española en sus gentes, costumbres y hablas, forma parte también de la construcción de un nacionalismo cultural no oficial basado en «la etnografía, concebida como el estudio, codificación e idealización de las culturas campesinas hasta convertirlas en el fundamento de la cultura nacional $»^{4}$.

Por ello, cabe considerar a Lafuente en una doble faceta de historiador. La primera la de creador de la Historia, con mayúscula y entendida como una actividad académica y científica, y la segunda como la de escritor de historias, con minúscula, relatos de hechos cotidianos con los que a la vez que critica la realidad política de su entorno, describe costumbres y entretiene. En las dos fue un maestro y creemos que no se puede entender la una sin la otra. La redacción de la historia como nación, del sujeto político que a mediados del siglo XIX reclama soberanía, adquiere mayor fuerza en la Historia General, pero empieza precisamente en la descripción del modo de ser español de la que encontramos trazos ya en el Fray Gerundio, periódico con el que inició su carrera literaria. Lafuente también toma parte activa en la política española desde 1843 siendo diputado por León en 1856 en las filas de la Unión Liberal y dando muestras de un liberalismo católico moderado. Al mismo tiempo empieza la redacción de la Historia General de España, y en este sentido, hay que matizar que la lucha por el relato del pasado es la lucha por el liderazgo político. La redacción de la Historia responde a la necesidad de definir la nación española, de reafirmar la soberanía mirando hacia un pasado en común que legitima tanto a políticos como a instituciones.

La historia en el siglo XIX debe atender al pueblo como base de la nación; toda la

\footnotetext{
${ }^{2}$ F. García de Cortázar, Los mitos de la historia de España, Barcelona, Editorial Planeta, 2004, p. 9.

${ }^{3}$ T. Pérez Viejo, ob. cit., p. 23.

${ }^{4}$ Idem.
} 
cultura conservada sirve al filósofo e historiador para que pueda descubrir el carácter del pueblo. Los ilustrados ven en la Grecia clásica

el espejismo imprescindible para fijar las posibilidades de un destino histórico y marcar su necesidad. Alcanzarlo es la tarea que la modernidad encomienda a la Historia -y esta es la segunda razón por la que este concepto es fundamental: promesa de felicidad futura que legitima tanta miseria presente ${ }^{5}$.

Para los románticos la literatura medieval se convierte en la época de la historia desde donde parte todo. Claro que en su contemplación se olvidaron de la realidad social de la Edad Media y solo quisieron representar la armonía imaginaria que los textos medievales intentan reflejar. Son estudios que interpretan la historia, cargados de opiniones en las que el historiador desfigura los hechos para darles apariencia mucho más valiosa y atractiva. La historia de España de Lafuente parte de la idea de que el determinismo geográfico origina la identidad del pueblo español: los españoles son un solo pueblo porque así lo determinó su territorio, y aunque haya una tendencia a la independencia y disgregación acabarán compartiendo un mismo destino y una misma religión.

¿Quién no descubre en la situación geográfica de España la particular misión que está llamada a cumplir en el desarrollo del magnífico programa de la vida del mundo? Cuartel el más occidental de Europa, encerrado por la naturaleza entre los Pirineos y los mares, divididas sus comarcas por profundos ríos y montañas elevadísimas, como delineadas y colocadas por la mano misma del gran artífice, parece fabricado su territorio para encerrar en sí otras tantas sociedades, otros tantos pueblos, otras tantas pequeñas naciones, que sin embargo han de amalgamarse en una sola y común nacionalidad, que corresponde a los grandes límites que geográficamente la separan del resto de las otras grandes localidades europeas. La historia confirmará los fines de esta física organización ${ }^{6}$.

Precisamente la religión siguió ligada al mito fundacional de España, y los historiadores y políticos del siglo xIX la mantuvieron en el discurso narrativo historicista para explicar la identidad y los rasgos culturales propios de los españoles. Ya en el momento de la publicación de los primeros volúmenes se le criticó que basara sus observaciones historicistas para defender la catolicidad del pueblo español y se decantara a favor de un liberalismo muy moderado. Tomás Bertrán Soler fue muy crítico con Lafuente acusándole, entre otras cosas, de redactar la Historia de España como si fuera todavía un fraile ${ }^{7}$. Valgan como ejemplo las palabas de la primera página

\footnotetext{
${ }^{5}$ M. Bozal Fernández, Necesidad de la ironía, Madrid, Visor, 1999, pp. 59-60.

${ }^{6}$ J. S. Pérez Garzón, Discurso preliminar. Historia General de España, Pamplona, Urgoiti Editores, 2002, p. 7.

7 «Tomás Bertrán Soler, activo militante del liberalismo revolucionario de 1835, autor de un bien documentado Atlas de España y Portugal, editado entre 1844 y 1846, escribió en 1858 una extensa refutación de la historia de Lafuente, con el significativo título de Cuchilladas a la capilla de fray Gerundio. Defensor de una democracia laica acusaba a Lafuente de seguir siendo fraile, porque «en todas las líneas de su historia resaltan las máximas que le inculcaron en el noviciado» (J. S. Pérez Garzón, ob. cit.,
} 
del discurso preliminar de la Historia General:

Por fortuna hay otro principio más alto, más noble, más consolador, a que recurrir para explicar la marcha general de las sociedades: la Providencia, que algunos no pudiendo comprenderla, han confundido por el fatalismo ${ }^{8}$.

Esto asienta el tono y la perspectiva de lo que será la Historia de Lafuente y que, como vemos, responde a las ansias de escribir una historia de España en la que el pueblo que se alzó en armas en contra de los ejércitos de Napoleón sea ahora el protagonista. Cuando Lafuente escribe el pasado mitifica la idea del pueblo español como indomable y resistente al invasor también desde tiempos inmemorables para legitimar su protagonismo en las contiendas contra los franceses a principios de siglo y sobre todo para crear una identidad nacional propia,

El valor primera virtud de los españoles, la tendencia al aislamiento, el instinto conservador y el apego a lo pasado, la confianza en su Dios y el amor a su bravura, la indisciplina, hija del orgullo y de la alta estima de sí mismo, esa especie de soberbia, que sin dejar de aprovechar alguna vez a la independencia colectiva la perjudica comúnmente por arrastrar demasiado a la independencia individual germen fecundo de acciones heroicas y temerarias, que así produce abundancia de intrépidos guerreros, como ocasiona la escasez de hábiles y entendidos generales, la sobriedad y templanza, que conducen al desapego del trabajo, todas estas cualidades que se conservan siempre, hacen de la España un pueblo singular que no puede ser juzgado por analogía9. (La cursiva es mía)

Como vemos, para Lafuente es imprescindible no solo ensalzar las características del pueblo español, la raza española a la que se refiere en ocasiones, sino que insiste en la unidad de todos los territorios en la península que a toda costa defiende el autor, incluido Portugal, lo que como advierte Pérez Garzón, «permite una lectura de sesgo expansionista $»^{10}$. A este respecto son numerosas las críticas a los reyes de Portugal en su relación con España.

Inconstante, como de costumbre, en sus resoluciones el rey don Fernando de Portugal, aunque atento siempre a su provecho, propuso a don Juan de Castilla que se anulase el ajustado casamiento de la hija de aquel, doña Beatriz, con uno de los hermanos bastardos del castellano, don Fadrique, duque de Benavente, solicitando que en lugar de éste se desposase con una hija el infante don Enrique que no tenía un año de edad $[\ldots]^{11}$.

\footnotetext{
p. LXXVI).

${ }^{8}$ Ibidem, p. 3.

${ }^{9}$ Ibidem, p. 8

${ }^{10}$ Ibidem, p. LXXXVI.

${ }_{11}$ M. Lafuente y Zamalloa, Historia General de España, (disponible en http://bibliotecavirtual-pdf. blogspot.com.es/2011/10/modesto-lafuente-historia-general-de.html [consultada abril, mayo, junio, 2017]), p. 544.
} 
Esta idea de unidad nacional va a ser central en toda la obra de Lafuente. Ya en el discurso preliminar traza una rápida genealogía de la historia de España insistiendo en cómo el pueblo se ha mantenido unido para combatir a los invasores y a los pueblos extranjeros que pretendían romper esa unidad. Es acertada manera de explicar el comportamiento heroico de los españoles en la guerra de la independencia: los españoles llevan el heroísmo en los genes. Por ejemplo al narrar la guerra contra Cartago,

El genio de la conquista se encontró con el genio de la resistencia, y a Aníbal, el mayor guerrero del siglo respondió Sagunto, la ciudad más heroica del mundo. De las ruinas humeantes de Sagunto salió una voz que avisó a las generaciones futuras de cuánto era capaz el heroísmo español. Transcurridos millares de años, el eco de otra ciudad de España, con ella todo el pueblo respondió a la voz de Sagunto, mostrando que al cabo de veinte siglos no había olvidado su alto ejemplo ${ }^{12}$.

Es sorprendente que para Lafuente los españoles ya estén constituidos como nación desde que Roma invadió la Península, y echa la culpa al carácter independiente de los íberos que esta fuera colonizada y esclavizada, lo que evidentemente le sirve para insistir una vez más en la importancia de la unidad de los pueblos de la península para que nuevas agresiones no debiliten al país,

Es el genio íbero, es la repugnancia a la unidad y la tendencia al aislamiento el que les hace forjarse sus cadenas. Hombres individualmente indomables, se harán esclavos por no unirse. Los veremos tenaces en conservar sus virtudes como sus defectos. Las mismas causas, los mismos vicios de carácter y de organización traerán en tiempos posteriores la ruina de España, o la pondrán al borde de su perdida ${ }^{13}$.

La insistencia de Lafuente en la unidad plantea algunas dudas, por lo menos al lector actual. Como explica Pérez Garzón a Lafuente «nunca se le ocurrió invertir la pregunta; si tenía que demostrar permanentemente la búsqueda de la unidad nacional, ¿no se debería a que esa unidad quizá no era tan natural como pretendía?» ${ }^{14}$. La perspectiva que construye de la realidad española se corresponde al discurso mítico y la idealización de la nación: España siempre ha sido un país especial, por geografía y por contar con la protección de la Providencia, y en ocasiones, cuando en el pasado el bienestar y la felicidad se han visto amenazados, los españoles permaneciendo unidos han vencido las hostilidades para poder construir un futuro común en donde se establezcan las bases de una sociedad libre y democrática. Es por ello que para Lafuente la invasión musulmana, por ejemplo, solo había de demorar por algún tiempo la unión de todos los pueblos de la Península. Baste citar lo que opina sobre

\footnotetext{
${ }^{12}$ J. S. Pérez Garzón, ob. cit., p. 13.

${ }^{13} \mathrm{Idem}$.

${ }^{14}$ Ibidem, p. LXXII. 
ella, «árabes y moros se derraman por todas las comarcas de la Península y la inundan como un río sin cauce. La nación ha desaparecido: ella resucitará» ${ }^{15}$.

La historia de España va dirigida al pueblo y a una emergente clase media, que necesita saber quién es, qué características componen su carácter y el papel que han tenido en la historia, y es por ello que Lafuente atribuye a España un origen desde tiempos primitivos construyendo así una percepción de nación con una cultura común, «por encima de la diversidad, se estaba fraguando un modelo de España como objeto internamente homogéneo, como Estado y sociedad externamente diferenciados» ${ }^{16}$. Las guerras que sufrió la Península durante los siglos son, según Lafuente, necesarias para poder alcanzar la independencia y la unidad.

Con la invasión árabe de la península se explica la razón de ser del cristianismo y Lafuente no tiene reparo en explicar que las batallas se ganaban con la ayuda de Santiago y es por ello que poco a poco los pueblos cristianos fueron conquistando los territorios. Con ello está mitificando la presencia del apóstol en España, algo que evidentemente es una falsedad, pero que tuvo una gran aceptación. El rigor histórico para Lafuente es un terreno pantanoso por sus particulares apreciaciones sobre la fe y los milagros, y la aceptación de textos bíblicos como textos academicistas ${ }^{17}$.

Como cabe esperar, la percepción de Lafuente de España en la Edad Media va a seguir el mismo modelo que hemos explicado anteriormente: defensa del catolicismo como rasgo inherente a la nación, la unión de los reinos de España por encima de la diversidad y las diferencias, dando siempre un mayor protagonismo a Castilla. Según él durante este periodo España es la primera nación en Europa en la posesión de códigos y en tener gobiernos en condiciones.

Honra es de esta nación que en una época en que la Europa gemía aún bajo el poder absoluto de los reyes, tuviera ella ya un sistema de gobierno con condiciones que hoy mismo agradecerían pueblos muy avanzados en la carrera de la civilización ${ }^{18}$.

Se refiere a Cataluña, Aragón y Valencia en segundo lugar, llamándolas «hermanas», y organizadas «también» sobre la base de la libertad con un sistema muy parecido al de Castilla. Para Lafuente la Edad Media es donde se forma la lengua y

\footnotetext{
${ }^{15}$ Ibidem, p. 36.

${ }^{16}$ Ibidem, p. LXXII.

${ }^{17}$ Las críticas a Lafuente por parte de Bertrán Soler venían precisamente por esta idea provincialista de la nación española. Bertrán Soler defendía una idea de España organizada como federación de pueblos y no una centralización política con Castilla como protagonista. «Pero sobre todo Bertrán soler refutó la pretensión de Lafuente de "refundir en Castilla todas las glorias de España", porque eso, a él, un federalista tan patriota como el que más, le parecía una impertinencia y la mayor necedad» (Ibidem, p. LXXIX).

${ }^{18}$ Ibidem, p. 61.
} 
la literatura nacional, y en general es donde España vive su vida religiosa, política e intelectual.

En su concepción de España Lafuente considera la diversidad nacional como propio de la manera de ser español. Valora las tradiciones locales y la diversidad cultural de España pero como características intrínsecas al hecho de ser español. Llama la atención por ejemplo que el título del capítulo XXII del volumen III se titule «Estado social de España. Castilla en el segunda mitad del siglo XIV» ${ }^{19}$, lo que indica la asociación clara entre Castilla y España, y la necesidad de la centralización política realizada por la monarquía. De ahí que Isabel de Castilla tenga un gran protagonismo, sin duda alguna para legitimar el reinado de Isabel II.

La escena cambia: la decoración se transforma; y vamos a asistir al magnífico espectáculo de un pueblo que resucita que nace a buena vida, que se levanta, que se organiza, que crece, que adquiere proporciones colosales, que deja pequeños a todos los pueblos del mundo, todo bajo el genio benéfico y tutelar de una mujer ${ }^{20}$.

Sin embargo esta particular visión providencialista y castellanizada de España no resta importancia a la labor investigadora hecha por Lafuente. Estudió en archivos y bibliotecas rescatando documentos y libros para incorporarlos a su obra. Como afirma López Serrano,

Conviene, antes de continuar con la recepción de la obra, recordar que Lafuente aportó un volumen de información inédita, nada despreciable, procedente de los archivos, y que, en cuanto a fuentes y bibliografía, se sirvió de gran parte del material disponible en su época, en el que habría que incluir lógicamente la misma herencia ilustrada y un poderoso influjo extranjero, de la mano todo ello de autores como Hume, Robertson o Guizot, o sea de los grandes renovadores de la concepción de la historia, cuyas obras se difundieron en España a partir de los años cuarenta del siglo XIX ${ }^{21}$.

Asimismo, amplió y algunas veces mejoró la historia del padre Mariana aportando nueva información y no tiene reparo en subrayar el descuido del anterior, ola equivocación de otros historiadores. Por ejemplo cuando trata de las leyes innovadoras que hizo Juan a al poco de ser entronizado rey de Castilla. Lafuente explica que entre las leyes suntuarias que estableció figura la de prescribir la calidad de las telas, adornos y vestidos de los caballeros, escuderos y ciudadanos, tanto en los trajes como en las armas y los arreos de los caballos. La nota al pie de página es bastante contundente,

El señor Sempere y Guarinos se equivoca citando como única ley suntuaria de este

\footnotetext{
${ }^{19}$ M. Lafuente y Zamalloa, ob. cit., p. 544.

${ }^{20}$ J. S. Pérez Garzón, ob. cit., p. 67.

${ }^{21}$ F. de A. López Serrano, «Modesto Lafuente como paradigma oficial de la historiografía española del siglo XIX: una revisión bibliográfica», Chronica Nova: Revista de historia moderna de la Universidad de Granada, 28 (2001), pp. 321-322.
} 
monarca (en su Historia del Lujo, página 165, edic. de 1783) una que dice haber dado en 1380, mandando que nadie sino los infantes pudiera traer vestidos de oro ni de seda, ni adornos de oro, plata, aljófar ni piedras; y añade que esta providencia, más que ley formal, era una especie de luto general que se mandaba guardar por la desgraciada pérdida de la batalla de Aljubarrota. En primer lugar, la batalla de Aljubarrota no se había dado en 1380, y en segundo lugar, la ley que nosotros citamos es anterior a la que cita el historiador jurisconsulto ${ }^{22}$.

Apreciamos cierto malestar en las palabras de Lafuente y sobre todo ganas de subrayar el error en la fecha de la batalla y ofrecer la exactitud de los hechos. De la misma manera procede con el padre Mariana hablando de las mismas cortes. Entre las muchas cosas justas que hizo Juan I, Lafuente resalta que se mandara a los alcaldes no consentir la vagancia ni la mendicidad. En nota a pie corrige a Mariana, con la clara intención de señalar lo inapropiado e inexacto de su versión, resaltando en contraste la precisión y certeza de la suya,

Mariana, hablando de estas cortes, se contenta con decir: «se establecieron en ellas muchas cosas: una, que el clérigo de menores órdenes casado pechase; pero que si fuese soltero, como traxese abierta la corona y hábito clerical, gozase del privilegio de la iglesia». Lib. XVIII., cap.3. Para Mariana no hubo en estas cortes otra cosa que mereciera ser mencionada ${ }^{23}$.

Estas puntualizaciones son a veces innecesarias, pero evidencian la gran labor investigadora de Lafuente y sobre todo su preocupación por citar las crónicas con exactitud y rigor científico. Justifican las horas de minucioso trabajo y lectura no solo de las crónicas que cita, sino también de las obras históricas precedentes a la Historia General. Delatan sin embargo la subjetividad del autor y la irritabilidad que le produce la inexactitud de datos, y en consecuencia, creemos que le restan algo del academicismo histórico y objetividad que pretende.

La redacción de la Historia recuerda en ocasiones la noticia periodística y en otras el relato. El estilo es sencillo y claro pero carece de objetividad, ya que los comentarios, opiniones y juicios de valor de Lafuente abundan en el texto. Lo cierto es que este peculiar estilo de narrar da agilidad al relato y en ocasiones lo convierte en una entretenida relación de acontecimientos. Es evidente la deuda del autor a los años de escritura periodística de carácter costumbrista.

El rey Armenio León v había sido cautivado por el Sultán de Babilonia. Mensajeros del cautivo monarca andaban solicitando la ayuda y favor de los príncipes cristianos para librarle del cautiverio. Dos de ellos, un prelado y un caballero, llegaron al rey de Castilla que estaba en Medina del Campo. Expuesto el objeto de su embajada, preguntó al rey qué cantidad sería necesaria para rescatar al ilustre prisionero, pues le cumplía hacer aquella buena obra. Respondiéronle los enviados que el

\footnotetext{
${ }^{22}$ M. Lafuente y Zamalloa, ob. cit., p. 511.

${ }^{23}$ Idem.
} 
príncipe de los infieles ni necesitaba ni quería dineros, sino que se pagaría más, y se tendría por más honrado con que los reyes cristianos le rogaran por la libertad del real cautivo, y le enviaran, si era posible, algún regalo de joyas otros objetos que no tenía en su tierra. Entonces don Juan dio a los mensajeros algunos falcones, gerifaltes, escarlatas, peñas-veras, (martas blancas), y varias alhajas de oro y plata, las mejores que pudo haber $[\ldots]^{24}$.

Mencionábamos anteriormente la doble faceta de historiador de Lafuente, una como historiador riguroso, y la segunda como escritor costumbrista de historias cotidianas de la realidad social española con una clara intención crítica. Parece que en la redacción de la Historia General esas dos facetas se funden en una en un estilo personal que informa y entretiene guiando a los lectores al reconocimiento de la identidad española y de la soberanía nacional originada en el pueblo. La acogida de su obra fue bien recibida por los sectores más moderados y conservadores del país,

Así, La Nación, órgano de Manuel Cortina, dirigente de la fracción más derechista del partido progresista, explicaba su identificación en los siguientes términos: «Inmensa es la satisfacción que sentimos todas las veces que comunicamos a nuestros lectores la publicación de un volumen de la más notable e importante obra que hoy sale de las prensas españolas. El trabajo del señor Lafuente es como esos edificios suntuosos que apenas empiezan a levantarse, ya se conoce su magnificencia y grandeza» ${ }^{25}$.

Las críticas más duras, como hemos visto anteriormente en Tomás Bertrán Soler, por ejemplo, provinieron del sector más radical del liberalismo español que no entendía la defensa de la catolicidad de la nación española en las páginas de una obra historicista y rigurosa que supuestamente trataba de mostrar los rasgos inextinguibles del carácter del pueblo español.

Con todo, la Historia General de España ha sido la historia del siglo xIx que se siguió utilizando en España hasta bien entrado el siglo xx y de la que bebieron escritores como Galdós para documentarse por ejemplo a la hora de escribir los Episodios Nacionales ${ }^{26}$.

Lafuente remontó a épocas inmemorables la identificación estado-nación con una evidente función mítica,

la historia como relato sobre los orígenes, como narración del mito fundacional.

\footnotetext{
${ }^{24}$ Ibidem, p. 512.

${ }^{25}$ J. S. Pérez Garzón, ob. cit., p. LXXIV.

${ }^{26}$ Como explica López Serrano, «Por su parte historiadores de relieve han coincidido en destacar la magnitud de la Historia General de España: Gooch nos recordaba que esta obra tenía la importancia que en Francia le correspondió a Henri Martin; Sánchez Alonso vio en ella la "historia general probablemente más leída"; Fontana considera a Lafuente, junto a Colmeiro, uno de los pocos historiadores "de verdad" de la mitad del siglo XIX; y, más recientemente, Inman Fox ha rubricado que esta obra pasa por ser "la historia general más difundida durante la segunda mitad del siglo XIX» (F. de A. López Serrano, art. cit., p. 320).
} 
Cuando la identidad colectiva ya no es la cristiandad sino la nación, el gran relato bíblico sobre los orígenes ya no sirve, se necesita otro alternativo, y es entonces cuando hacen su aparición las historias nacionales ${ }^{27}$.

La Historia General de Lafuente fue una narración eficaz porque ofrecía una visión del proceso de construcción de la nación española que tiene en cuenta las necesidades políticas del momento fundamentadas en la unidad política y social de España bajo la protección, eso sí, de la Providencia.

Pero la influencia de Lafuente, como decía al empezar este trabajo, sigue en vigor hoy en día. Felipe vi en el 40 aniversario de la democracia celebrado el 28 de junio de este año 2017 en el congreso de los Diputados advertía de la importancia de salvaguardar la convivencia y que «ningún camino que emprenda nuestra democracia puede - ni debe- conducir a una ruptura de la convivencia» ${ }^{28}$. Añadía que la mejor protección de esta convivencia es respetar las normas que la amparan. Estas palabras en pro de la unidad hay que entenderlas dentro del ambiente independentista que se vive en el país y aseguran que dentro del contexto democrático español hay que proteger la unidad de todos los pueblos de España. Como vemos, la base de las palabras de Felipe vi está fundamentada en las mismas premisas que defendía Lafuente. El discurso estuvo centrado, de hecho, en los dos últimos siglos de España, precisamente cuando se estaba construyendo la identidad del pueblo español desde la redacción de una de las historias de España más importantes de los últimos tiempos. Y como vemos con una gran repercusión. El discurso de Felipe vi podría resumirse en las palabras de Lafuente con las que encabezamos este trabajo, «Lo presente, producto del pasado, engendra a su vez el futuro». Como vemos, el discurso nacionalista español sigue siendo el mismo y continúa insistiendo en la indivisibilidad de España como nación. El discurso mítico que se instauró con Lafuente para garantizar la soberanía del pueblo español y dotarle de rasgos únicos e imperecederos sigue vigente hoy en día. Los mitos de la historia de España, el mito de la unificación Estado-nación que Lafuente remonta al reinado de los Reyes Católicos no se ha desvanecido, y vive en el colectivo ideológico del pueblo. Parte de la idea de que cada una de las intervenciones que los distintos reyes han aportado al destino y construcción de España es una opción ideológica a favor de la monarquía como forma de gobierno. Si los reyes no eran ejemplares se justificaba con la ley providencial que llevaba a la sociedad española al perfeccionamiento aprendiendo de los errores. Así la relación de los distintos reyes en el medievo es siempre positiva, aunque las crónicas adviertan que el gobierno del

\footnotetext{
${ }^{27}$ T. Pérez Viejo, ob. cit., p. 191.

${ }^{28}$ M. Alberola, «El Rey: “Fuera de la ley solo hay arbitrariedad, imposición e inseguridad"», El País Digital, 28 de junio (2017) [consultado 28 de junio. 2017], en http:/ / politica.elpais.com/politica/2017/06/28/ actualidad/1498635499_604471.html
} 
monarca no fuera ejemplar. En el caso de Pedro de Castilla Lafuente reconoce que el monarca tuvo a veces un comportamiento depravado, pero la Providencia supo juzgarle. El tono compungido de Lafuente y la descripción detallada de la conducta del monarca llevan de la mano al lector haciendo a este partícipe de la escena que está narrando.

Angústiase el alma, y se estremece la mano, y tiembla la pluma al haber de trazar el cuadro y hacer el análisis razonado y crítico del reinado de don Pedro de Castilla: y esto no solamente por la cadena casi no interrumpida de trágicas escenas y horribles suplicios, y sangrientas ejecuciones a que se dejó arrastrar este violento monarca, con razón y justicia unas veces, por venganza otras, otras por impetuosidad de carácter, y las más por una especie de ferocidad orgánica: no solamente por las revueltas, las perturbaciones y las calamidades que afligieron la monarquía castellana en este periodo: sino porque entre todos los actores y personajes de este complicado drama de cerca de veinte años [...] En este como en aquel reinado se ve palpable y sensiblemente la mano de la Providencia haciendo expiar a cada uno sus excesos y crímenes ${ }^{29}$.

Lafuente apela a los sentimientos más que a la razón, pero así era cómo se debía construir el discurso mítico nacionalista en el siglo xIx. Se trata de demostrar la continuidad de un carácter a través de los siglos y es por ello que el relato de Lafuente tiene características comunes con el de las historias caballerescas. Su intención era que los rasgos étnicos del pueblo español permanecieran y sobre todo que se diferenciaran de otros rasgos étnicos. Y no hay que olvidar que además había que insistir en la unidad, porque solo con un pueblo unido se podían vencer los males que siempre amenazan a la sociedad y al gobierno que la dirige. Desde los diferentes partidos políticos que ha habido en el gobierno de la nación española democrática después de la muerte de Franco, se ha intentado construir el gran proyecto de España siguiendo el modelo propuesto por Lafuente desde las páginas de su Historia General. Se utiliza aún el discurso mítico nacionalista insistiendo en el carácter nacional y la importancia de la convivencia dentro del marco de la legalidad, una cuestión que fue de vital importancia para Lafuente.

\section{Bibliografía}

Alberola M., «El Rey: "Fuera de la ley solo hay arbitrariedad, imposición e inseguridad”», El País digital, 28 de junio (2017), [última consulta 28 de junio, 2017]:

http://politica.elpais.com/politica/2017/06/28/actualidad/1498635499_604471. html

Álvarez Junco, J., Mater Dolorosa. La idea de España en el siglo XIX, Madrid, Penguin Random House, 2015.

${ }^{29}$ M. Lafuente, ob. cit., p. 544. 
Bozal Fernández, M., Necesidad de la ironía, Madrid, Visor, 1999.

Fuertes Arboix, M., La sátira política en la primera mitad del siglo xix: Fray Gerundio de Modesto Lafuente (1837-1842), Alicante, Universidad de Alicante, 2014.

García de CorTÁzAr, F., Los mitos de la historia de España, Barcelona, Editorial Planeta, 2004.

Lafuente y ZamalloA, M., Historia General de España, Biblioteca digital Moratín [consultada abril, mayo, junio, 2017]:

(http:/ / bibliotecavirtual-pdf.blogspot.com.es/2011/10/modesto-lafuentehistoria-general-de.html).

LÓPEZ SERRANO, F. de A., «Modesto Lafuente como paradigma oficial de la historiografía española del siglo xIX: una revisión bibliográfica», Chronica Nova: Revista de historia moderna de la Universidad de Granada, 28 (2001), pp. 315-336.

, De los orígenes a Pelayo. Modesto Lafuente en su contexto historiográfico. Tesis Doctoral. Málaga, Universidad de Málaga, 2013.

Pérez Garzón, J. S., Discurso preliminar. Historia General de España, Pamplona, Urgoiti Editores, 2002.

PÉREZ Vejo, T., Nación, identidad nacional y otros mitos nacionalistas, Oviedo, Ediciones Nobel, 1999. 